\title{
The Effect of Two Methods of Pomegranate (Punica granatum L) Juice Extraction on Quality During Storage at $4^{\circ} \mathrm{C}$
}

\author{
Graça Miguel, Susana Dandlen, Dulce Antunes,* Alcinda Neves, and Denise Martins \\ Campus de Gambelas, Faculdade de Engenharia de Recursos Naturais, \\ Universidade do Algarve, 8005-139 Faro, Portugal
}

Received 3 March 2004; revised 22 June 2004; accepted 22 June 2004

\begin{abstract}
The effect of two extraction methods of pomegranate juice on its quality and stability was evaluated. The first method consisted of separation of the seeds from fruits and centrifugation. The second method consisted of squeezing fruit halves with an electric lemon squeezer. During a period of 72 hours of cold storage at $4^{\circ} \mathrm{C}$, the juices were evaluated for the presence of sugars, organic acids, and anthocyanins. Delphinidin 3-glucoside was identified to be the major anthocyanin present at the level of 45-69 mg/L. Among the organic acids, oxalic and tartaric acids dominated. The major sugars detected in pomegranate juice were glucose and sucrose. No significant differences in the content of sugars, organic acids, or anthocyanins in juices obtained through application of the two different extraction methods were detected, with the exception of the drastic decrease of cyanidin 3, 5-diglucoside level in juice obtained by seed centrifugation. The $\mathrm{pH}$ did not show differences between treatments. Titrable acidity and the level of sugars expressed as ${ }^{\circ}$ Brix decreased after 32 and 15 hours after extraction, respectively, when juice was obtained by centrifuging the seeds.
\end{abstract}

\section{INTRODUCTION}

Phenolic compounds are important components of many fruits, vegetables, and beverages contributing to their colour and sensory properties. Epidemiological studies have demonstrated that the composition of phenol-rich food retards the progression of arteriosclerosis and reduces the incidence of heart diseases by preventing the oxidative stress, that is, lipid peroxidation in arterial macrophages and in lipoproteins [1,2]. More recently, some authors reported that anthocyanins decreased cadmium accumulation in liver and kidney, the concentration of bilirubin and urea in blood serum, and aspartate aminotransferase and alanine aminotransferase activities [3].

Pomegranate juice is an important source of phenolic compounds, with anthocyanins being one of the most important, especially the 3-glucosides and 3,5diglucosides of delphinidin, cyanidin, and pelargonidin [4]. These components along with gallagyl-type tannins, ellagic acid derivatives, and other hydrolysable tannins could contribute in some way to the antioxidant activity of pomegranate juice [2].

"Assaria" pomegranate is a Portuguese variety cultivated in the southern region of the country. Its edible seeds are a favourite snack due to sweet taste and tenderness, and its fruits are mainly used for direct consump- tion. However, they could also be used for production of fruit juices or production of processed products such as jams, jellies, syrups, or carbonated beverages [5]. At present the damaged fruits, with cracks, cuts, or bruises in the husk, are discarded. Their application for the production of processed food products could improve the economic yield of this crop.

The composition of pomegranate juice depends on cultivar type, environmental and postharvest factors, and storage and processing factors $[2,6,7,8,9,10]$.

Although Assaria pomegranate is the main Portuguese variety, the composition of its juice is not yet well studied. The objective of our research is to evaluate the composition of the Assaria pomegranate juices obtained using two different extraction methods and their effect on the juice quality during storage over 72 hours at $4^{\circ} \mathrm{C}$.

\section{MATERIALS AND METHODS}

\section{Fruits and treatments}

Sweet pomegranates (Punica granatum cv Assaria) were harvested in a commercial orchard in eastern $\mathrm{Al}-$ garve. Fruits were transported on the same day to the laboratory at the University of Algarve. The damaged fruits were removed and the healthy fruits of uniform size and appearance were washed and randomly distributed into groups of 10 fruits for juice extraction. 
To obtain juice, two extraction methods were applied. The first method consisted of manually peeling the fruits, separating the seeds, and extracting the juice by a Phillips Electric juice centrifuge. In the second method, fruits were cut in two halves and the juice was immediately extracted using a Phillips Electric lemon squeezer. Each extraction was replicated 4 times.

The obtained juices were immediately stored at $4^{\circ} \mathrm{C}$ in the dark. Samples were collected at 0, 5, 15, 32, 48, and 72 hours after extraction. At each sampling point, the juices were analysed for ${ }^{\circ} \mathrm{Brix}$ (which is a percentage by weight of sugar in a solution at room temperature), $\mathrm{pH}$, titrable acidity, anthocyanins, sugars, and organic acids. The changes in colour were monitored according to the Munsell Colour Chart [11].

\section{Standards and reagents}

Delphinidin 3,5-diglucoside (Dp3,5), delphinidin 3-glucoside (Dp3), cyanidin 3,5-diglucoside $(\mathrm{Cy} 3,5)$, cyanidin 3-glucoside (Cy3), pelargonidin 3, 5-diglucoside $(\mathrm{Pg} 3,5)$, and pelargonidin 3-glucoside (Pg3) standards were purchased from Apin Chemicals Ltd, UK. Methanol (HPLC gradient grade) was purchased from SigmaAldrich Quimica, SA (Spain). Formic, oxalic, tartaric, pyruvic, malic, ascorbic, maleic, citric, fumaric, and sulphuric acids glucose, and fructose were purchased from Riedel-de-Haën (Germany). The ultrapure water was purified with the MilliQ system, from Millipore, USA.

\section{Titrable acidity, $\mathrm{pH}$, and ${ }^{\circ}$ Brix}

Titrable acidity was calculated as percentage of citric acid by titrating $10 \mathrm{~mL}$ of the pomegranate juice with a solution of $\mathrm{NaOH}(0.1 \mathrm{~N})$ till $\mathrm{pH}$ 8.1. The $\mathrm{pH}$ was measured by a $\mathrm{pH}$ meter (Crison micropH 2001-Crison Instruments, SA (Spain)). The level of sugars was measured as ${ }^{\circ}$ Brix by a digital refractometer, model PRI-Atago Co LTD (Japan).

\section{Anthocyanins}

The juice sample ( $1 \mathrm{~mL}$ ) was centrifuged for 2 minutes at $10000 \mathrm{rpm}$ and filtered through a $0.45 \mu \mathrm{m}$ filter (Millipore). The identification of anthocyanins was performed by HPLC with a System Gold Programmable Detector Module 166-UV-Vis (Beckman Coulter, USA), using a LiChroCART 100 RP- 18 column $(25 \mathrm{~cm} \times 0.4 \mathrm{~cm}$ i.d.; $5 \mu \mathrm{m}$ particle size; Merck (Germany)). The mobile phase was $5 \%$ formic acid (A) and methanol (B) in a linear gradient from $15 \%$ to $35 \%$ B at 15 minutes, followed by isocratic run until 20 minutes. The flow rate was $1 \mathrm{~mL} / \mathrm{min}$. Chromatograms were recorded at absorbance of $510 \mathrm{~nm}$. The different anthocyanins were identified by comparison of their retention times with those of pure standards. The concentrations of anthocyanins were calculated from standard curves of Dp3, 5, Dp3, Cy3, 5, Cy3, Pg3, 5, and $\mathrm{Pg} 3$, at four concentrations $(0.01,0.02,0.04,0.08 \mathrm{mg} / \mathrm{L})$. Injection volume was $20 \mu \mathrm{L}$ using an injector with a $20 \mu \mathrm{L}$ loop (Rheodyne, USA).

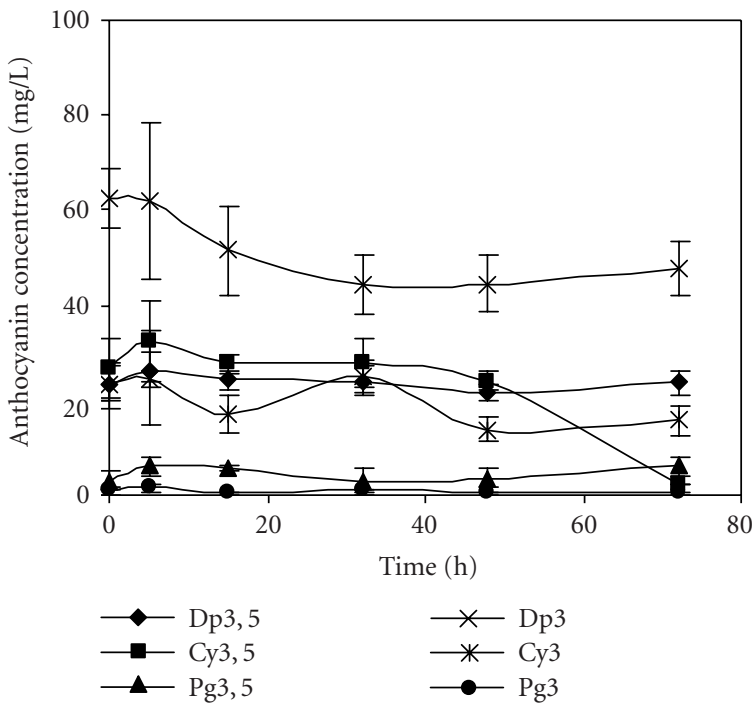

FIgURE 1. Evolution of concentration of anthocyanins present in the pomegranate juice obtained by seed centrifugation and stored for 72 hours at $4^{\circ} \mathrm{C}$. Bars represent standard deviation of 4 replications.

\section{Sugars and organic acids}

To determine the content of sugars and organic acids in juice, samples $(1 \mathrm{~mL})$ were centrifuged for 20 minutes at $13000 \mathrm{rpm}$ and filtered through a $0.45 \mu \mathrm{m}$ filter (Millipore). The composition of sugars and acids was detected with an HPLC (Beckman) equipped with a Jasco (Japan) refractive index (RI) 1530 detector. The column Polyspher OA HY $(30 \mathrm{~cm} \times 0.65 \mathrm{~cm}$ i.d.; $9 \mu \mathrm{m}$ particle size $)$ from Merck was used at $35^{\circ} \mathrm{C}$. The mobile phase consisted of $0.0025 \mathrm{~N} \mathrm{H}_{2} \mathrm{SO}_{4}$ applied at a flow rate of $0.4 \mathrm{~mL} / \mathrm{min}$. The injection volume was $20 \mu \mathrm{L}$ using an injector with a $20 \mu \mathrm{L}$ loop (Rheodyne). The different sugars and organic acids were identified by comparison of their retention times with those of pure standards. The concentrations of these compounds were calculated from standard curves of the respective sugars and organic acids.

\section{RESULTS AND DISCUSSION}

The levels of major anthocyanins detected in pomegranate juices obtained through two different extraction methods, centrifugation of seeds or squeezing of fruit halves with an electric lemon squeezer, and stored at $4{ }^{\circ} \mathrm{C}$ over 72 hours are presented in Figures 1 and 2. No significant differences in the composition of anthocyanins were detected among the treatments. In both cases, the main anthocyanin was Dp3, followed by Dp3,5, Cy3,5, and Cy3. Pg3, 5 and Pg3 were present in the lowest amounts. The anthocyanins detected in our analysis of the Assaria pomegranate juices were as identified in other cultivars [12]; however, concentrations of the individual pigments differed. 


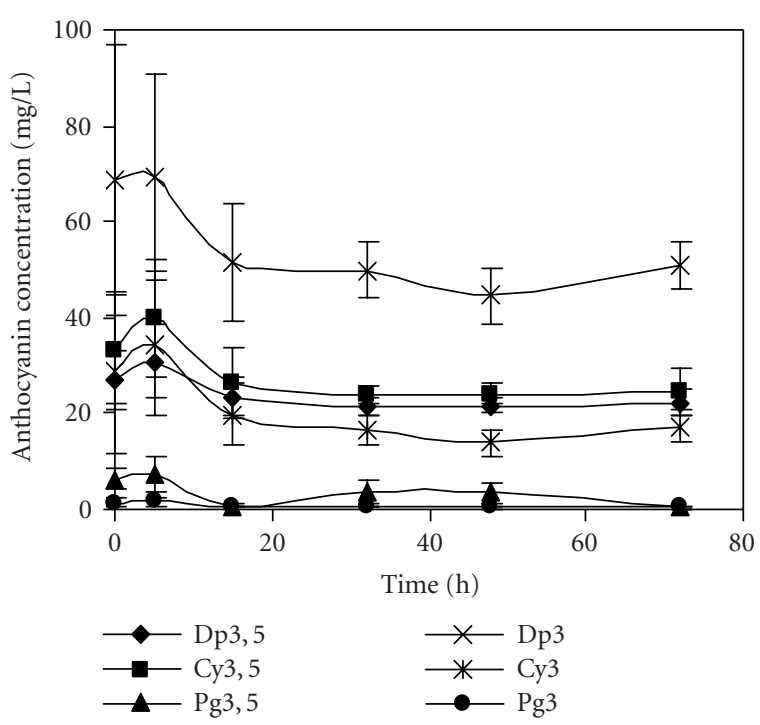

FIGURE 2. Evolution of concentration of anthocyanins present in the pomegranate juice obtained by squeezing of fruit halves with an electric lemon squeezer and stored for 72 hours at $4^{\circ} \mathrm{C}$. Bars represent standard deviation of 4 replications.

Colour is one of the most important parameters when making a sensorial evaluation of food quality. No significant differences were observed between the colours of juices obtained through various extraction methods. At the extraction time, the Assaria juice colour was noted as $53 \mathrm{~A}$, according to the Munsell Colour Chart. The juice colour did not change during experimental time.

The bright colour of pomegranate fruit and juice is due to anthocyanins, so their stability through juice processing is of major importance. The anthocyanin content in both extraction methods was similar as was the respective evolution profile over time. During the first 5 hours of storage at $4^{\circ} \mathrm{C}$, a slight increase $(0.3 \%-4 \%)$ in the amounts of each anthocyanin was registered, followed by a decrease in the next ten hours and then stabilisation occurred. Additionally, the fruit juice obtained by centrifugation of seeds showed a pronounced decrease of $\mathrm{Cy} 3,5$, mainly after 48 hours of storage (Figure 1). It was reported previously that in POM Wonderful pomegranate juices the diglucoside anthocyanins were more stable than the monoglucosides [8], therefore the high decrease of Cy3, 5 observed in our experiment was unexpected.

The main organic acids present in the pomegranate juices were oxalic and tartaric acids, either in juices obtained by seed centrifugation or by squeezing of fruit halves, respectively (Figures 3 and 4). These results were quite different from those reported by others $[6,13]$ for 11 Spanish pomegranate cultivars in which citric acid was the main organic acid, sometimes followed closely by malic acid. Oxalic and tartaric acids were present only in small amounts. In contrast, a great variation in the organic acid composition among the Turkish pomegranate cultivars has been reported [14]. Cit-

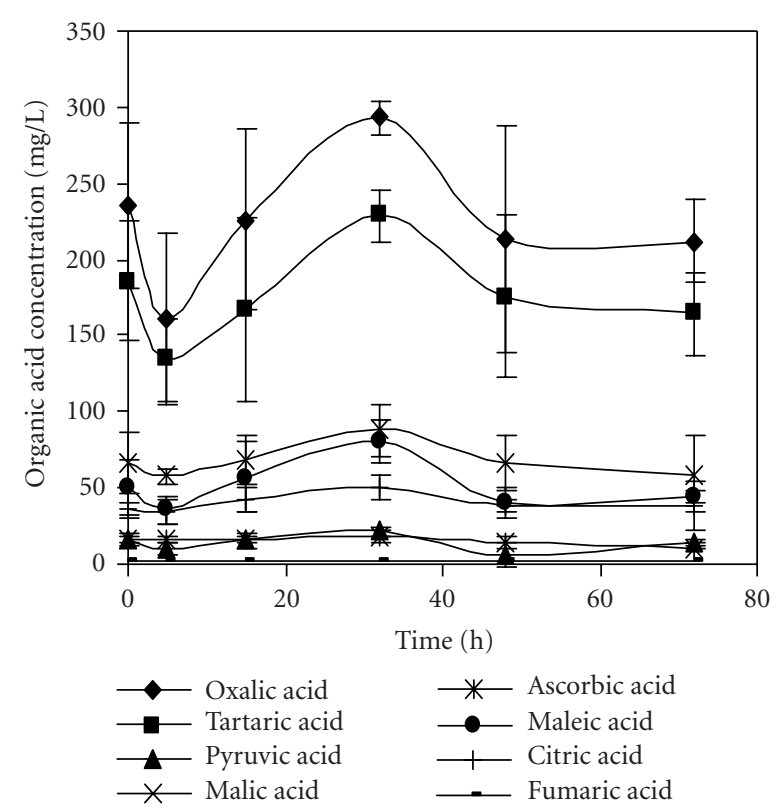

Figure 3. Evolution of concentration of organic acids present in the pomegranate juice obtained by seed centrifugation and stored for 72 hours at $4^{\circ} \mathrm{C}$. Bars represent standard deviation of 4 replications.

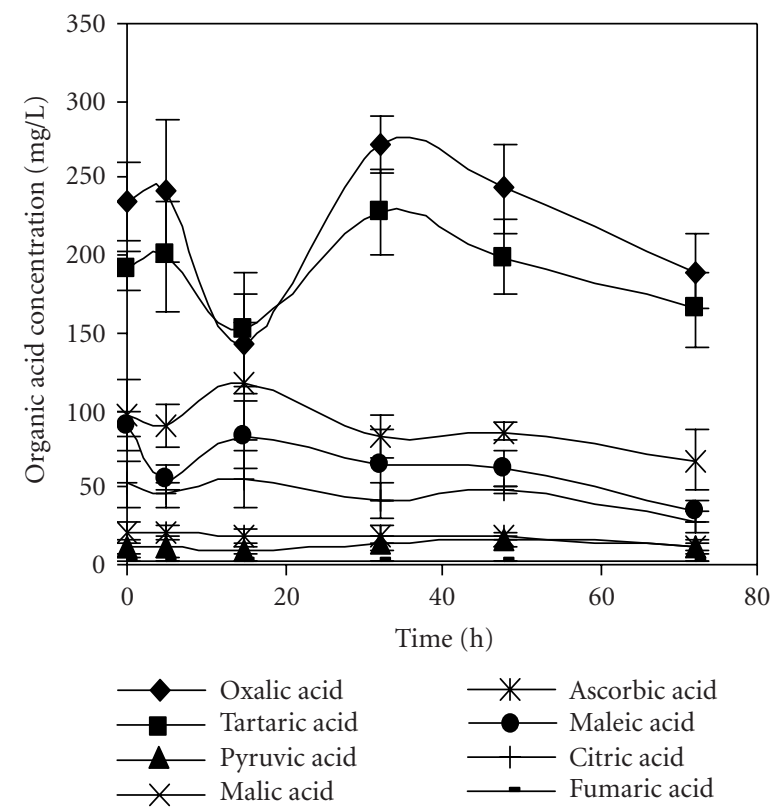

FIGURE 4. Evolution of concentration of organic acids present in the pomegranate juice obtained by squeezing of fruit halves with an electric lemon squeezer and stored for 72 hours at $4^{\circ} \mathrm{C}$. Bars represent standard deviation of 4 replications.

ric and malic acids were predominant in the majority of varieties, but in some cultivars large amounts of oxalic and tartaric acids were detected. In those varieties, only one had oxalic acid as the major organic acid. 


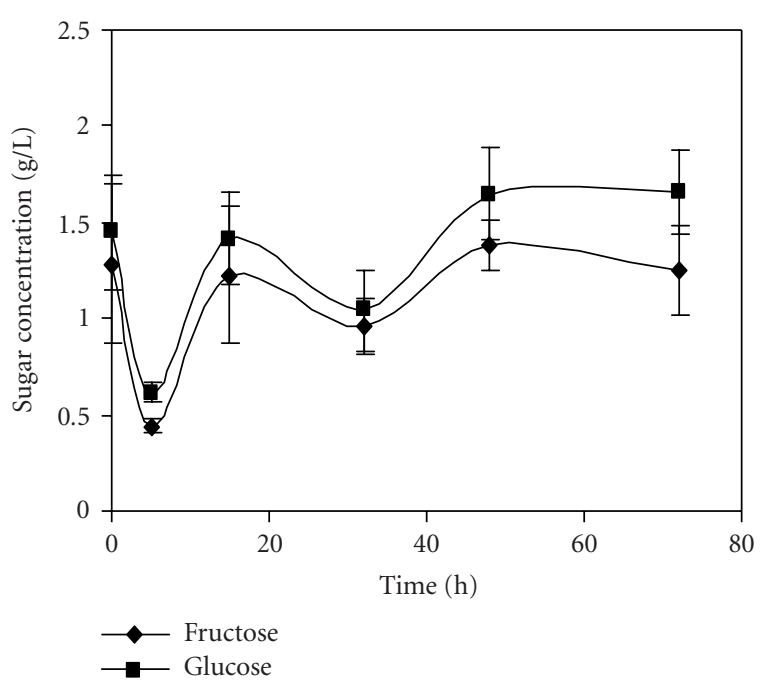

Figure 5. Evolution of sugar concentration in the pomegranate juice obtained by seed centrifugation and stored for 72 hours at $4^{\circ} \mathrm{C}$. Bars represent standard deviation of 4 replications.

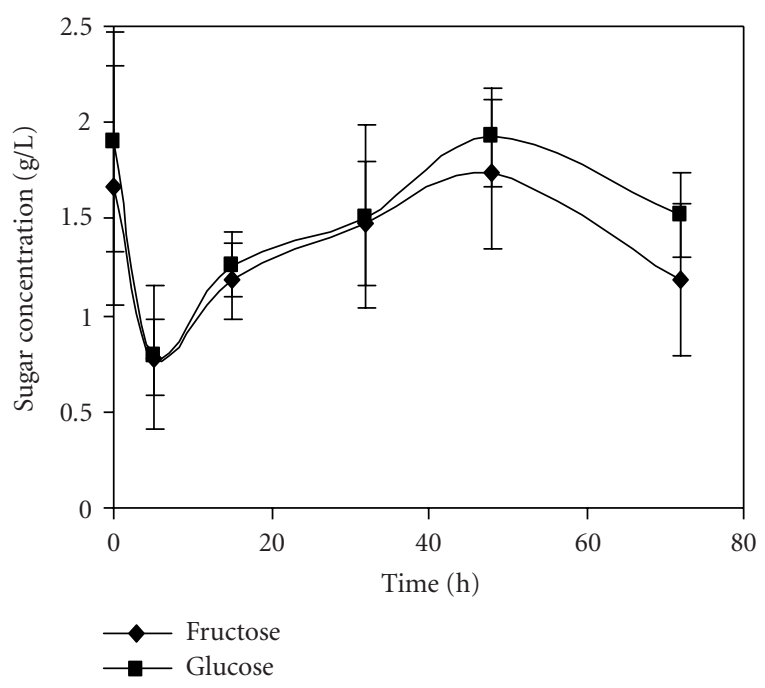

FIGURE 6. Evolution of sugar concentration in the pomegranate juice obtained by the squeezing of fruit halves with an electric lemon squeezer and stored for 72 hours at $4^{\circ} \mathrm{C}$. Bars represent standard deviation of 4 replications.

The evolution profiles of organic acids over time in juices obtained through application of both methods were quite similar, with only a few exceptions. A decrease of each organic acid during the first 5-15 hours of cold storage was observed, followed by an increase reaching the maximal values after 32 hours of storage. At this point, the levels of oxalic acid were of 292.9 and $271.1 \mathrm{mg} / \mathrm{L}$ and those of tartaric acids were of 228.9 and $228.0 \mathrm{mg} / \mathrm{L}$ in juices obtained by seed centrifugation and squeezing of fruit halves, respectively. The exceptions reported above were malic, maleic, and citric acids in the samples ob-

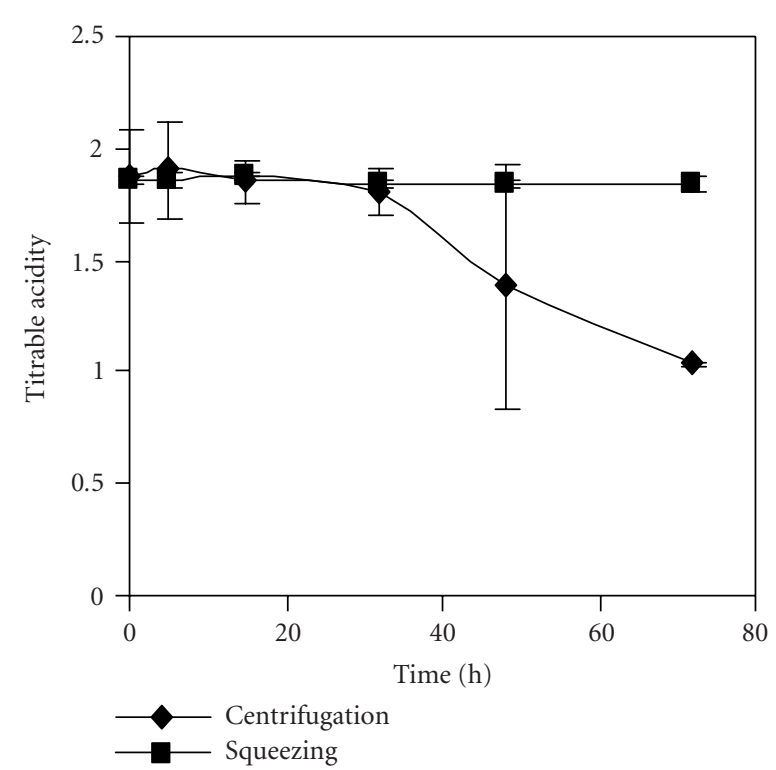

Figure 7. Evolution of titrable acidity as percentage of citric acid in the pomegranate juices obtained by centrifugation of seeds and by the squeezing of fruit halves with an electric lemon squeezer and stored for 72 hours at $4^{\circ} \mathrm{C}$. Bars represent standard deviation of 4 replications.

tained by squeezing the fruits, and ascorbic acid in those obtained through application of both methods (Figure 4). The concentrations of malic and citric acids reached the maximum after 15 hours of storage. The highest level of maleic acid was observed just after juice extraction. The ascorbic acid content remained quite stable over the whole storage period independently of the method application.

The main carbohydrates detected in the pomegranate juices were glucose and fructose (Figures 5 and 6). This supports previously reported results for other pomegranate cultivars [6]. Only traces of sucrose were found and therefore sucrose was not considered in the present work. The amounts of glucose and fructose were quite similar in juices obtained through application of both methods. A pronounced decrease of total carbohydrate content of about $50 \%$ was observed in juices independently of the extraction method after 5 hours of storage at $4^{\circ} \mathrm{C}$. It can be assumed that the decrease of sugar and organic acids content during the first 15 hours of storage occurs due to de novo synthesis of anthocyanins, whose level increased exactly at the same time in juices obtained through both methods.

Titrable acidity showed a clear decrease after 32 hours of storage when juice was obtained by centrifuging the seeds, that was less marked in the juice extracted by squeezing fruits (Figure 7). The level of sugars measured as ${ }^{\circ}$ Brix changed over time but the main feature was the sharp decrease after 15 hours until the end of the experiment in the seed centrifugation procedure (Figure 8). This behaviour may be related to the different chemical composition of juices due to the presence of tannins as a result 


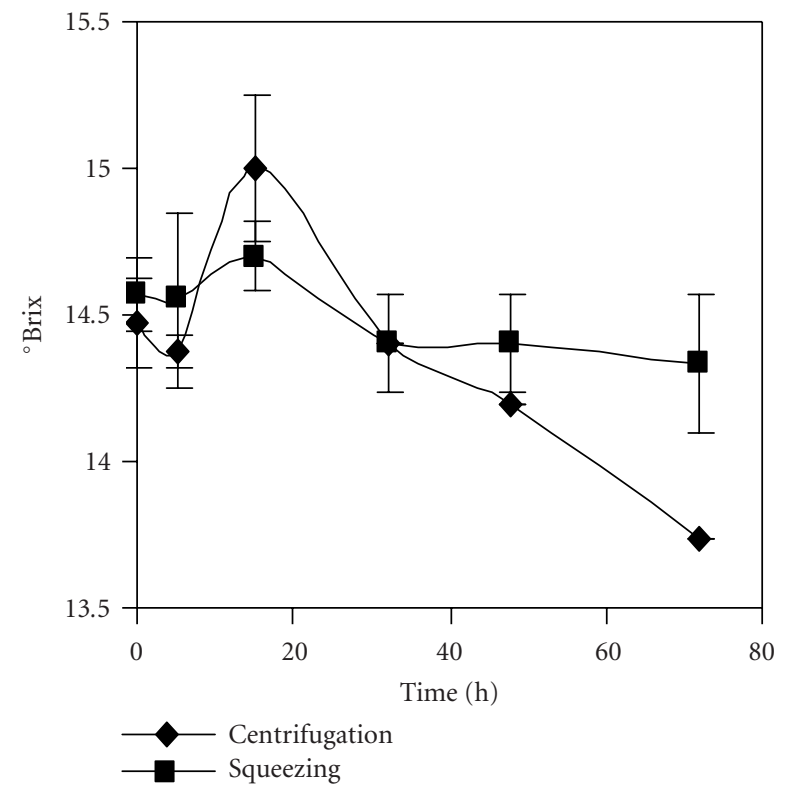

FIGURE 8 . Evolution of ${ }^{\circ}$ Brix of pomegranate juices obtained by centrifugation of seeds and by the squeezing of fruit halves with an electric lemon squeezer and stored for 72 hours at $4^{\circ} \mathrm{C}$. Bars represent standard deviation of 4 replications.

of rind cell damage during fruit squeezing. The presence of tannins is the main problem when juices are extracted from whole fruits. As a result, a bitter taste develops that must be corrected by industrial processing [15]. In our experiment, according to panelist evaluation of the fresh juices, the juice obtained by fruit squeezing showed a bitter taste in comparison to the sweet taste of the juice obtained by centrifuging seeds.

The $\mathrm{pH}$ presented a slight increase over time, more pronounced from 5 to 15 hours after extraction (Figure 9). There were no differences in $\mathrm{pH}$ related with the method used for juice extraction. This could partially explain the relative stability of anthocyanins found in the juices obtained by both extraction methods.

Both methods used for pomegranate juice extraction did not affect the evaluated characteristics of juice quality; namely, the anthocyanins content, the juice colour, the organic acids and sugars composition, as well as the $\mathrm{pH}$ values. Squeezing unpeeled fruit halves is the most economical and easy method to use. The juice obtained by that method was more stable over time as indicated by the titrable acidity and ${ }^{\circ}$ Brix determinations. The main disadvantage of the squeezing method is the production of juice with bitter taste if additional treatments are applied. Besides, the bitterness could be overcome because the actual trend in juice production is the blending of several fruit juices. Additionally, the use of Assaria pomegranate in fruit juice mixtures will be beneficial for human health in reducing the risk from oxalic acid consumption [16].

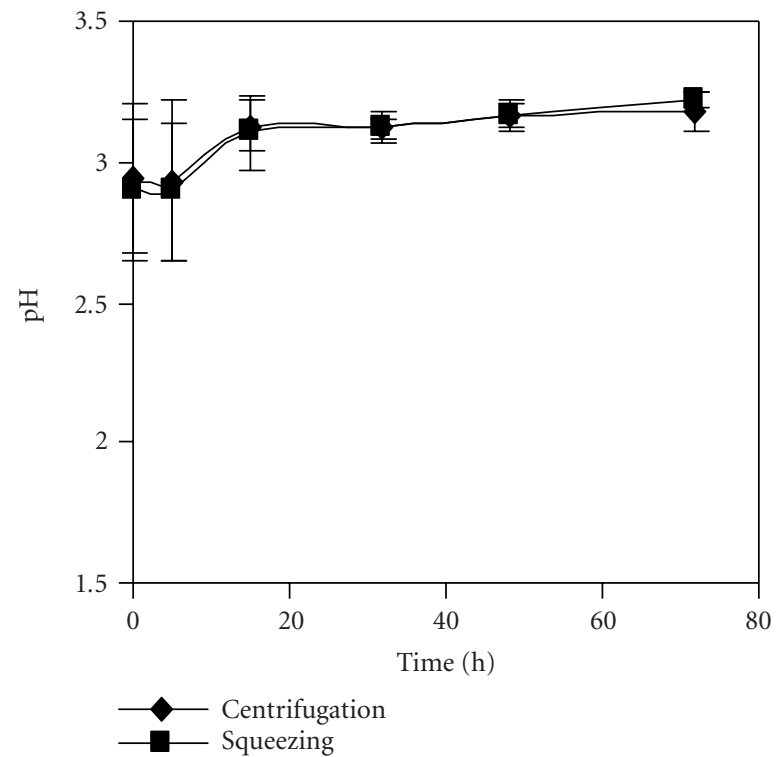

Figure 9. Evolution of $\mathrm{pH}$ of pomegranate juices obtained by centrifugation of seeds and by the squeezing of fruit halves with an electric lemon squeezer and stored for 72 hours at $4^{\circ} \mathrm{C}$. Bars represent standard deviation of 4 replications.

\section{REFERENCES}

[1] Aviram M, Rosenblat M, Gaitini D, et al. Pomegranate juice consumption for 3 years by patients with carotid artery stenosis reduces common carotid intima-media thickness, blood pressure and LDL oxidation. Clin Nutr. 2004;23(3):423-433.

[2] Gil MI, Tomas-Barberan FA, Hess-Pierce B, Holcroft DM, Kader AA. Antioxidant activity of pomegranate juice and its relationship with phenolic composition and processing. J Agric Food Chem. 2000;48(10):4581-4589.

[3] Kowalczyk E, Kopff A, Fijałkowski P, et al. Effect of anthocyanins on selected biochemical parameters in rats exposed to cadmium. Acta Biochim Pol. 2003;50(2):543-548.

[4] Du CT, Wang PL, Francis FJ. Anthocyanins of pomegranate, punica granatum. J Food Sci. 1975;40 (2):417-418.

[5] Maestre J, Melgarejo P, Tomás-Barberán FA, GarciaViguera C. New food products derived from pomegranate. Options Medit. 2000;42:243-245.

[6] Melgarejo P, Salazar DM, Artés F. Organic acids and sugars composition of harvested pomegranate fruits. Eur Food Res Technol. 2000;211(3):185-190.

[7] Heshi AB, Garande VK, Wagh AN, Katore HS. Effect of pre-harvest sprays of chemicals on the quality of pomegranate fruit (Punica granatum L) cv G-137. Agric Sci Digest. 2001;21(1):25-27.

[8] Holcroft DM, Gil MI, Kader AA. Effect of carbon dioxide on anthocyanins, phenylalanine ammonia lyase and glucosyltransferase in the arils 
of stored pomegranates. J Amer Soc Hort Sci. 1998;123(1):136-140.

[9] Nanda S, Sudhakar Rao DV, Krishnamurthy S. Effects of shrink film wrapping and storage temperature on the shelf life and quality of pomegranate fruits cv Ganesh. Postharvest Biol Technol. 2001;22 (1):61-69.

[10] Ozkan M. Degradation of anthocyanins in sour cherry and pomegranate juices by hydrogen peroxide in the presence of added ascorbic acid. Food Chem. 2002;78(4):499-504.

[11] Munsell Colour Co. Munsell Book of Colour. Matter Finish Collection. 1976, Baltimore, Md.

[12] Gil MI, Garciá-Viguera C, Artés F, Tomás-Barberán FA. Changes in pomegranate juice pigmentation during ripening. J Sci Food Agri. 1995;68:77-81.

[13] Legua P, Melgarejo P, Martnez M, Hernández F. Evolution of sugars and organic acid content in three pomegranate cultivars (Punica granatum L). Options Medit. 2000;42:99-104.

[14] Poyrazoğlu E, Gokmen V, Artik N. Organic acids and phenolic compounds in pomegranates (Punica granatum L) grown in Turkey. J Food Compos Anal. 2002;15(5):567-575.

[15] Vardin H, Fenercioğlu H. Study on the development of pomegranate juice processing technology: clarification of pomegranate juice. Nahrung. 2003;47(5):300-303.

[16] Gregus Z, Klaassen CD. Mechanisms of toxicity. In: Casarett and Doull's Toxicology: The Basic Science of Poisons. New York, NY: McGraw-Hill; 1996:35-74.

* Corresponding author.

E-mail: mantunes@ualg.pt

Fax: +351 28981 8419; Tel: +351289800100 

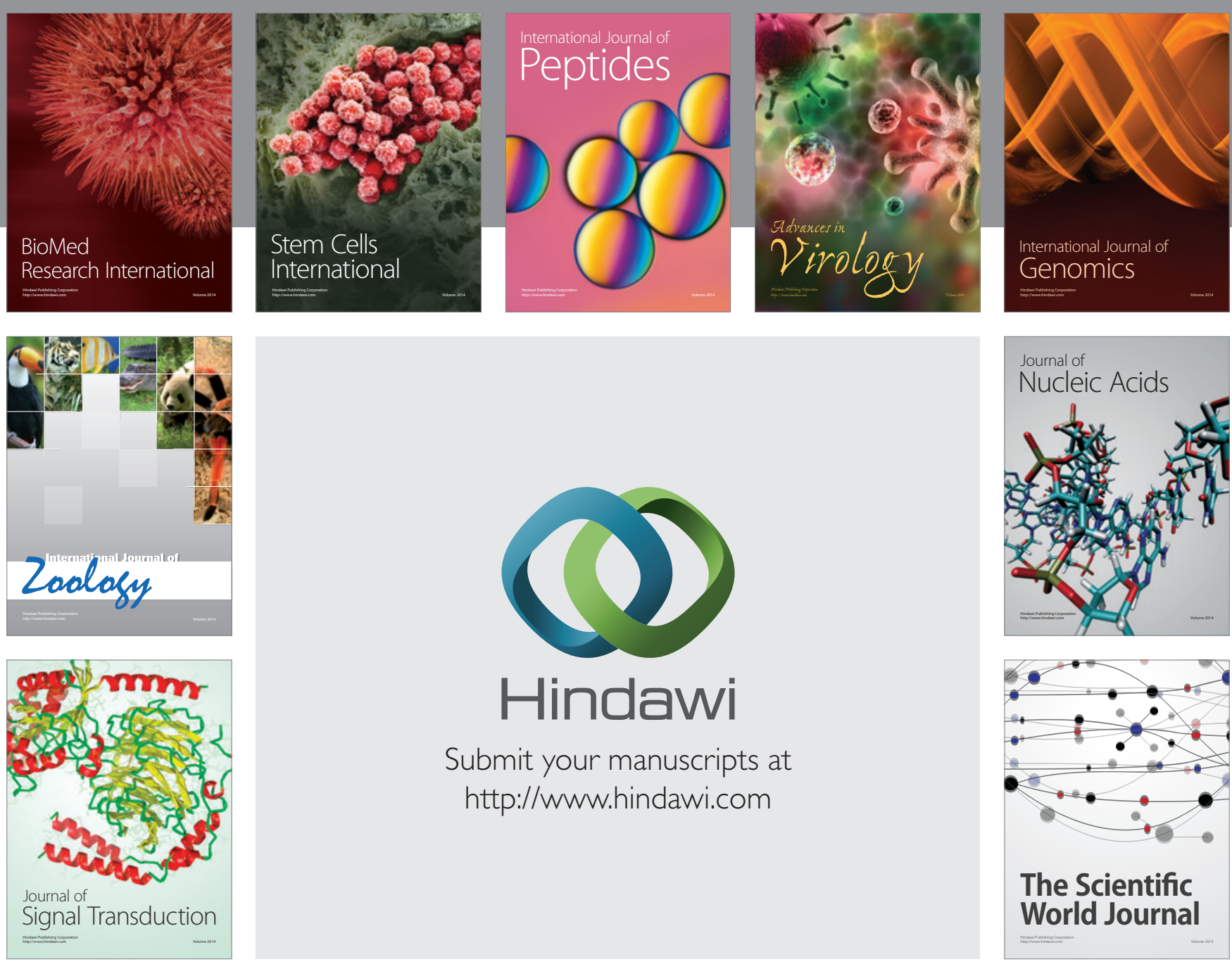

Submit your manuscripts at

http://www.hindawi.com
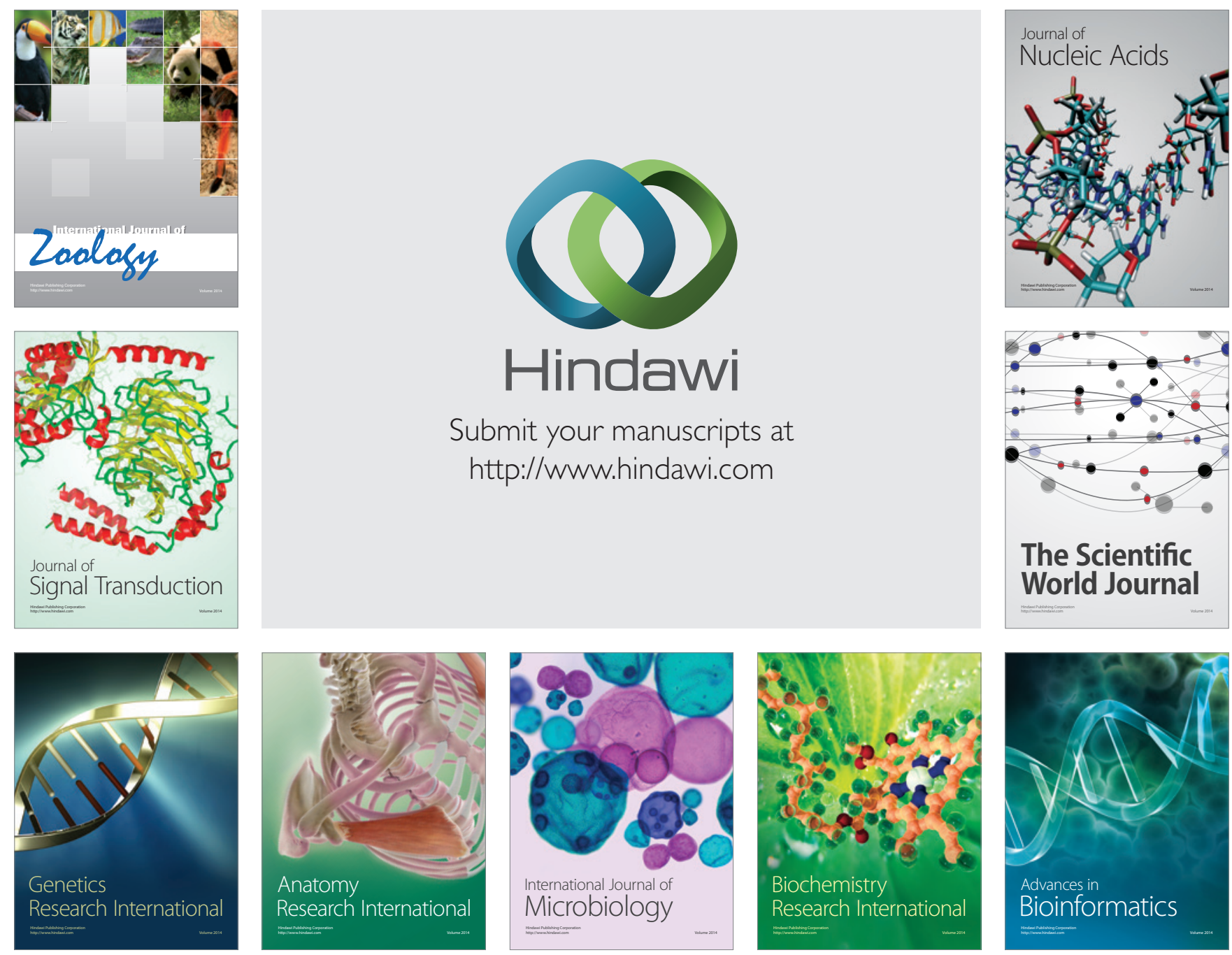

The Scientific World Journal
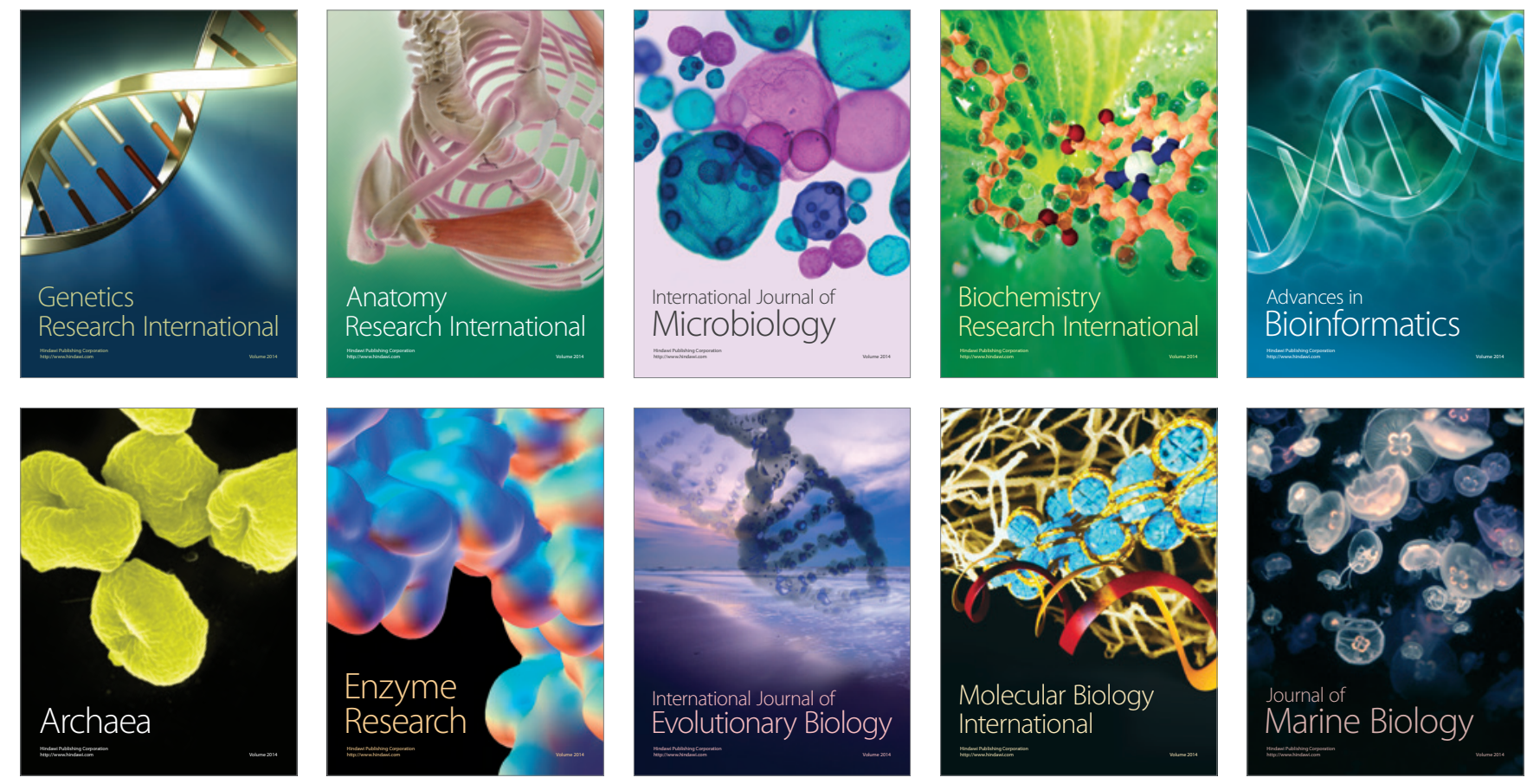